Tropical Journal of Pharmaceutical Research March 2021; 20 (3): 491-496

ISSN: $1596-5996$ (print); 1596-9827 (electronic)

(C) Pharmacotherapy Group, Faculty of Pharmacy, University of Benin, Benin City, 300001 Nigeria.

Available online at http://www.tjpr.org

Original Research Article

http://dx.doi.org/10.4314/tjpr.v20i3.7

\title{
Effect of CBX4/miR-137/Notch1 signaling axis on the proliferation and migration of breast cancer cells
}

\author{
Le Ma1, Lihua Zheng ${ }^{2}$, Dongmei Zhang ${ }^{2}$, Zhimin Fan ${ }^{1 *}$ \\ ${ }^{1}$ Department of Breast Surgery, The First Hospital of Jilin University, Changchun 130024, Jilin Province, ${ }^{2}$ National Engineering \\ Laboratory for Druggable Gene and Protein Screening, Northeast Normal University, Changchun, Jilin Province 130024, China \\ *For correspondence: Email: eqtv73@163.com
}

Sent for review: 21 November 2020

Revised accepted: 21 February 2021

\begin{abstract}
Purpose: To study the effect of CBX4/miR-137/Notch1 signaling axis on the migration and proliferative capacity of breast cancer.

Methods: Breast cancer MCF7 cell lines were cultured in vitro and transfected with CBX4overexpressed plasmid and interfering plasmid, which served as CBX4 over-expressing group and CBX4 interfering group, respectively. A control group (blank plasmid transfection) was set up. The MCF7 cells were transfected with miR-137 over-expressed plasmid, miR-137 interfering plasmid and Notch1 interfering plasmid, which served as miR-137 over-expressing, miR-137 interference and Notch1 interference groups, respectively. Cell proliferation and migration capacity were determined with methylthiazolyldiphenyl-tetrazolium (MTT) method and Transwell migration assay, respectively, while reverse transcription-polymerase chain reaction (RT-PCR) and immunoblotting were used to assay related gene expressions.

Results: Cell migration in CBX4 over-expressing group was significantly raised $(p<0.05)$. The expression of miR-137 in CBX4 over-expressing group was markedly decreased $(p<0.05)$. Compared with the control group, mRNA and protein expressions of Notch1 (NICD), Hey2 and Jag1 in miR-137 over-expressing cells were increased in the miR-137 interfering group $(p<0.05)$.

Conclusion: CBX4 level is increased in mammary cancer cells. Moreover, CBX4 enhances cell proliferation and migration through induction of Notch1 signaling route by inhibiting miR-137 expression. These findings provide a new strategy for clinical therapy of mammary cancer.
\end{abstract}

Keywords: $C B X 4 / m i R-137 /$ Notch1 signaling axis, Breast cancer, Proliferation, Migration

\begin{abstract}
This is an Open Access article that uses a fund-ing model which does not charge readers or their institutions for access and distributed under the terms of the Creative Commons Attribution License (http://creativecommons.org/licenses/by/4.0) and the Budapest Open Access Initiative (http://www.budapestopenaccessinitiative.org/read), which permit unrestricted use, distribution, and reproduction in any medium, provided the original work is properly credited.
\end{abstract}

Tropical Journal of Pharmaceutical Research is indexed by Science Citation Index (SciSearch), Scopus, International Pharmaceutical Abstract, Chemical Abstracts, Embase, Index Copernicus, EBSCO, African Index Medicus, JournalSeek, Journal Citation Reports/Science Edition, Directory of Open Access Journals (DOAJ), African Journal Online, Bioline International, Open-J-Gate and Pharmacy Abstracts

\section{INTRODUCTION}

Breast cancer is the most common cancerous disease in women. In developing countries, breast cancer ranks second in the number of female deaths caused by cancer [1]. The incidence of breast cancer which accounts for 7 to $10 \%$ of all malignant tumors, has been increasing year by year, and has begun to affect younger women in recent years [2]. The occurrence of breast cancer is the result of multifactor and multi-stage synergism. Breast cancer cells have strong invasive ability and high degree of malignancy. However, the pathogenesis of breast cancer has not yet been fully understood. It is generally believed that breast cancer is 
affected by a combination of genetic and environmental factors. Moreover, since breast tissue can be influenced by the proliferationenhancing effects of estrogens and progesterone, the risk of breast cancer in women is significantly higher than that in men, thereby seriously affecting women physically and mentally, and even endangering their lives [3,4]. Therefore, it is clinically important to investigate the molecular mechanisms involved in breast cancer proliferation and metastasis, and to find new therapeutic targets so as to prolong the survival time of patients.

Polycomb gene protein family comprises transcription factors that participate in several biological events. They regulate the expressions of target genes through epigenetic modification at the chromatin level, and they usually function in the form of complexes. Studies have found that Chromobox homolog (CBX) in classical complexes is linked to the pathogenesis of tumors [5]. MicroRNAs (miRNAs) are small noncoding RNAs involved in the regulation of biological processes such as cell growth, differentiation, transformation and apoptosis [6]. The Notch1 signaling pathway is vital for cell proliferation and regulation of angiogenesis, and also plays an important role in the pathogenesis of breast cancer [7]. The influence of CBX4/miR$137 /$ Notch1 signaling axis on the proliferative and migration abilities of breast cancer cells was investigated in this research.

\section{EXPERIMENTAL}

\section{Experimental reagents and instruments}

The materials, reagents and instruments used, and their suppliers (in bracket) were: breast cancer MCF7 cell line (Shanghai Institute of Cell Sciences, Chinese Academy of Sciences); whole protein extraction reagent (Beijing Solarbio Technology Co. Ltd); ECL chromogenic reagent (Shanghai Xinfan Biotechnology Co. Ltd); DAB color developing kit (Shanghai Jizhi Biochemical Technology Co. Ltd); Neutral gum (Beijing Biolab Technology Co. Ltd); MTT detection kit (Shanghai Yubo Biotechnology Co. Ltd); Protein Marker (Shanghai Yamei Biotechnology Co. Ltd); RNA Reverse transcription kit (Shanghai Runwell Industrial Co. Ltd); Plasmid extraction kit (Beijing Tianmo Technology Development Co. Ltd), and Liposome 2000 (Beijing Chreagen Biotechnology Co. Ltd).

The others were digital display thermostatic water bath (Shanghai Chenlian Biotechnology Development Co. Ltd.); various types of pipette (Brand (Shanghai) Trading Co. Ltd); inverted phase contrast microscope (Nanjing Beideng Medical Co. Ltd); PCR amplification instrument (Shanghai Fuze Trading Co. Ltd); Western blot electrophoretic instrument (Beijing Junyi Electrophoresis Equipment Co. Ltd); Vortex Mixer (Suzhou Epitope Biotechnology Co. Ltd); desktop refrigerated centrifuge (Beijing Qianming Gene Technology Co. Ltd), and horizontal swing decolorizing shaker (Shanghai Yihui Biotechnology Co. Ltd).

\section{Cell transfection and grouping}

Breast cancer MCF7 cells were cultured at $37{ }^{\circ} \mathrm{C}$ and $5 \% \mathrm{CO}_{2}$ in DMEM that contained $10 \%$ FBS. When the cells attained 80 to $90 \%$ confluence, they were sub-cultured. Cells at logarithmic growth phase were used for subsequent studies. Liposome 2000 reagent was used to transfect CBX4 over-expressed plasmid and interfering plasmid into breast cancer cell lines. These served as CBX4 over-expressing group and CBX4 interference group, respectively. A control group (blank plasmid transfection) was also set up.

\section{Determination of cell proliferation}

The cells were re-suspended in $0.25 \%$ trypsin and inoculated in 96-well plates (2000 cells per well). When the cells were adherent to the wall for $24 \mathrm{~h}$, they were treated with MTT solution (5 $\mathrm{mg} / \mathrm{mL}, 100 \mu \mathrm{L} /$ well), followed by continuous culturing for $4 \mathrm{~h}$. Then, the medium was discarded and replaced with $120 \mu \mathrm{L}$ of dimethyl sulfoxide. The cells were placed on a shaker for $10 \mathrm{~min}$, after which the absorbance (OD) value at $490 \mathrm{~nm}$ was determined using a multifunctional microplate reader. Then, a cell growth curve was plotted using Excel.

\section{In vitro clone formation experiment}

The cells were re-suspended in $0.25 \%$ trypsin and inoculated in 6 -well plates (500 cells per well). The medium was changed every 3 days and the cells were cultured for 3 weeks. Thereafter, the medium was discarded, and following PBS-rinsing (thrice), the cells were fixed in methanol for $20 \mathrm{~min}$. Then, they were incubated with $0.1 \%$ crystal violet for $20 \mathrm{~min}$, rinsed thrice with PBS and dried. The cell colonies were observed under a microscope (more than 50 cells were counted as one colony).

\section{Transwell migration assay}

The cells were subjected to $0.25 \%$ trypic digestion, rinsed thrice in FBS-free DMEM and made into a suspension, $200 \mu \mathrm{L}$ of which was 
put in upper Transwell chamber, while the lower chamber had $20 \%$ FBS-containing DMEM. Incubation was done for 24 to $48 \mathrm{~h}$. Then, the upper chamber was rinsed with PBS, fixed with methanol for $15 \mathrm{~min}$, soaked in $0.1 \%$ crystal violet solution for $10 \mathrm{~min}$, and washed 3 times with PBS

The cells in the upper chamber were wiped off. Then, 5 fields of view were selected at random under an inverted microscope. The mean cell count was taken as the number of migrating cells.

\section{Determination of gene expression}

Total RNA was extracted from logarithmic growth cells with TRIzol method, and its content and integrity were determined. Reverse transcription reaction was carried out according to the operating procedure of Invitrogen reverse transcription kit. After the reaction, the prepared cDNA was amplified using PCR, with GAPDH as reference gene. The $\mathrm{Ct}$ value of each target gene was obtained. The reaction conditions were: predenaturation at $95{ }^{\circ} \mathrm{C}$ for $10 \mathrm{~min}, 95{ }^{\circ} \mathrm{C}$ for $30 \mathrm{~s}$, $60{ }^{\circ} \mathrm{C}$ for $30 \mathrm{~s}$, extension at $72{ }^{\circ} \mathrm{C}$ for $2 \mathrm{~min}$, with a total of 40 cycles, and preservation at $4{ }^{\circ} \mathrm{C}$. The formula $2^{-\triangle \triangle C T}$ was used for the relative quantification of gene data.

\section{Determination of protein expression with western blot assay}

Tissue proteins were extracted from logarithmic growth cells, and BCA kit was used to determine the protein content. Then, $15 \mu \mathrm{g}$ of total protein was subjected to SDS-PAGE electrophoresis and transferred to PVDF membrane which was then sealed by incubation with $5 \%$ skim milk for $1 \mathrm{~h}$.

Then, the membrane was incubated with diluted primary antibody at $4{ }^{\circ} \mathrm{C}$ overnight, and rinsed with TBST buffer, followed by incubation with $2^{\circ}$ antibody for at least $1 \mathrm{~h}$, and washing 3 times with TBST buffer. Electrochemical luminescence reagent was used for color development and exposure, and the protein bands were scanned, developed and quantified.

\section{Statistical analysis}

Data are presented as mean \pm SD. Comparison of mean values between two groups was done with independent sample $t$-test, while ANOVA was used for multiple group comparison. Values of $p<0.05$ were taken as indication of statistical significance. The data from this study were analyzed using SPSS20.0 software package.

\section{RESULTS}

\section{Effect of CBX4 on proliferation of breast cancer cells}

The results of MTT assay showed that cell proliferation activity of MCF7 cells in CBX4 overexpressing group were significantly increased, while the cell proliferation activity of MCF7 cells in CBX4 interference group were markedly reduced, relative to control $(p<0.05)$. In vitro clone formation experiments confirmed that cell clone population in MCF7 cells of CBX4 overexpressing group was markedly higher, while cell clone population in MCF7 cells of CBX4 interfering group was markedly reduced, relative to control value. These results are shown in Figure $1 \mathrm{~A}$ and $\mathrm{B}$.

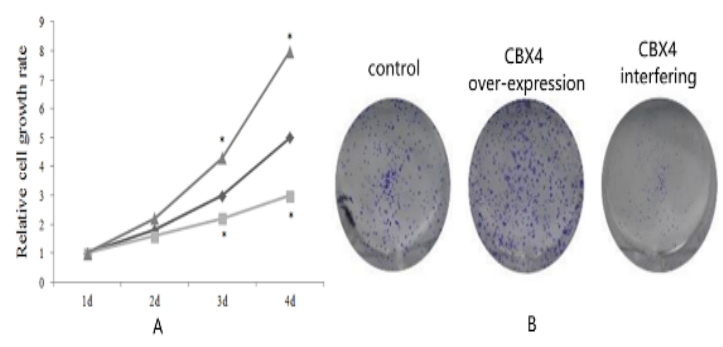

Figure 1: Effect sof $\mathrm{CBX} 4$ on proliferation of breast cancer cells. (A). Cell proliferation activity, as measured using MTT assay. (B) Number of cell clones, as determined using in vitro clone formation assay. $\$$ : control group; $\mathrm{CBX} 4$ over-expression group; $\Delta$ CBX4 Interfering group. ${ }^{*} P<0.05$, vs control

\section{Influence of CBX4 on cell migration of breast cancer cells}

The population of migrated MCF7 cells in CBX4 over-expressing group was markedly raised, while it was significantly decreased in the CBX4 interfering group, relative to control (Figure 2).

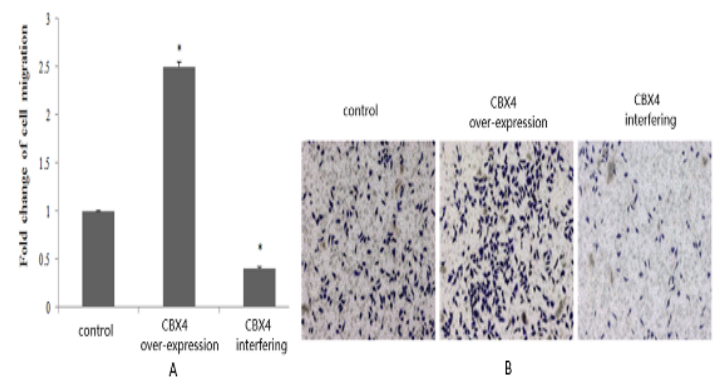

Figure 2: Migration ability of breast cancer cells, as determined using Transwell migration assay. ${ }^{*} P<$ 0.05 , vs control 
Influence of CBX4 on miR-137 expression in breast cancer cells

Results from RT-PCR assay showed that miR137 level in CBX4 over-expressing group was markedly reduced, while miR-137 level in CBX4 interfering group was significantly increased (Figure 3).

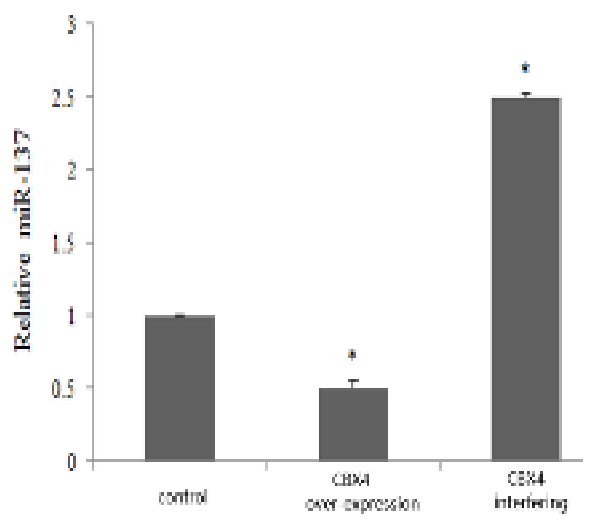

Figure 3: Relative expression of miR-137, as assayed using RT-PCR method. * $P<0.05$, vs control

\section{Effect of miR-137 on Notch1 signal route in mammary cancer cells}

The mRNA and protein expressions of Notch1 (NICD), Hey2 and Jag1 in the miR-137 overexpressing group were markedly decreased $(p<$ $0.05)$, while they were markedly increased in the miR-137 interfering group, relative to control $(p<$ 0.05, Table 1).

\section{Effect of CBX4 targeting miR-137 on Notch1 signaling pathway}

When Notch1 interfering plasmid was transfected into MCF7 cells, clonal formation experiment and Transwell migration experiment revealed that the population of cell clones and cell migration in the Notch1 interfering + CBX4 and miR-137 + CBX4 groups were markedly decreased. These results are shown in Figure 4.

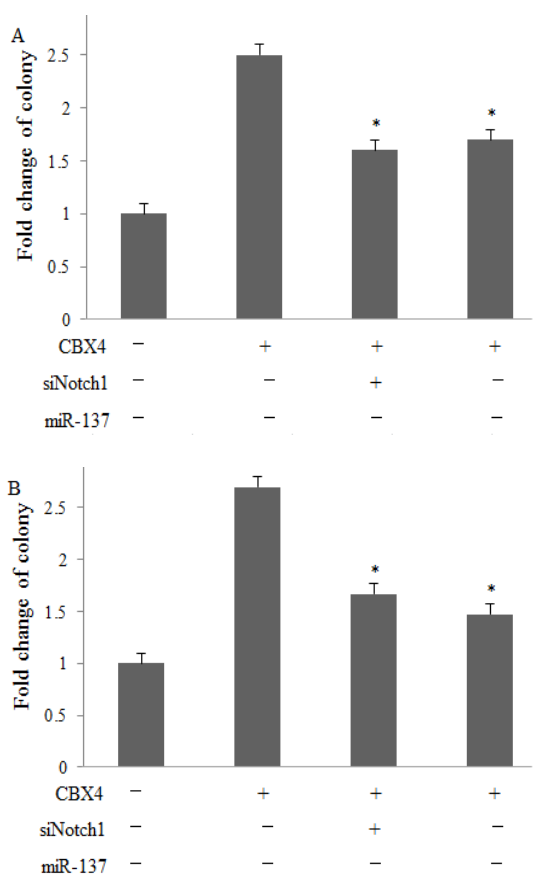

Figure 4: Effect of CBX4 targeting miR-137 on Notch1 signaling pathway. (A) In vitro clone formation experiment; (B) Transwell migration experiment. ${ }^{*} P<$ 0.05, compared with CBX4 group

\section{DISCUSSION}

In recent years, with the extensive clinical application of systematic and comprehensive treatment measures during operation and after operation, the survival rate of breast cancer patients has been improved.

However, there are still $30 \%$ of early breast cancer patients with recurrence and metastasis, which not only increase difficulty in clinical treatments, but also seriously affect the quality of life and physical and mental health of patients [8]. Therefore, it is particularly crucial to identify molecular targets for timely detection and therapy of breast cancer. It is known that CBX4 is an important component of polycomb gene protein family which is located on human chromosome 17

Table 1: Effect of miR-137 on Notch1 (NICD), Hey2, Jag1 mRNA and protein in breast cancer cells

\begin{tabular}{lcccccc}
\hline \multirow{2}{*}{ Group } & \multicolumn{2}{c}{ Notch1 (NICD) } & \multicolumn{2}{c}{ Hey2 } & \multicolumn{2}{c}{ Jag1 } \\
& mRNA & Protein & mRNA & Protein & mRNA & Protein \\
\hline Control & $1.00 \pm 0.02$ & $1.01 \pm 0.02$ & $1.02 \pm 0.03$ & $1.04 \pm 0.05$ & $1.00 \pm 0.02$ & $1.01 \pm 0.03$ \\
MiR-137 Over- & $0.42 \pm 0.05^{*}$ & $0.41 \pm 0.04^{*}$ & $0.39 \pm 0.06^{*}$ & $0.40 \pm 0.07^{*}$ & $0.42 \pm 0.05^{*}$ & $0.43 \pm 0.06^{*}$ \\
expressing & $2.45 \pm 0.43^{*}$ & $2.92 \pm 0.36^{*}$ & $2.88 \pm 0.65^{*}$ & $2.56 \pm 0.13^{*}$ & $2.85 \pm 0.36^{*}$ & $2.99 \pm 0.48^{*}$ \\
MiR-137 Interfering & 174.65 & 391.65 & 117.76 & 1519.67 & 364.67 & 230.11 \\
$F$ & $<0.001$ & $<0.001$ & $<0.001$ & $<0.001$ & $<0.001$ & $<0.001$ \\
$P$-value & & & & & &
\end{tabular}


As the only active enzyme protein in this family, the role of CBX4 in tumor is related to its multiple unique domains, and it participates in control of cell proliferation, differentiation, transformation and other biological functions in vivo $[9,10]$. Some scholars have found that CBX4 is upregulated in liver cancer patients, and the survival rate of these patients is markedly low, when compared to low-expression patients. This can be used as an independent factor to determine the prognosis of liver cancer patients [11]. Other studies have found that CBX4 is highly expressed in osteosarcoma cells and clinical tissues, and can promote osteosarcoma growth by activating transcriptional activity of hypoxia-inducible factor $1 \alpha$, leading to poor prognosis in patients [12].

However, there are limited reports on levels of CBX4 in mammary cancer, and the mechanism involved. In this study, in vitro cell experiments showed that cell proliferation activity, number of cell clones and population of migrated cells in CBX4 over-expressing group were markedly raised, relative to control values, while cell proliferation activity, number of cell clones and population of migrated MCF7 cells in the CBX4 interfering group were decreased, relative to control. These results indicate that CBX4 is present at a high level in breast cancer cells and can promote cell proliferation and migration.

In recent years, miRNA has become increasingly relevant in tumor development. It inhibits and degrades mRNA translation by complementing and pairing with the bases of target gene mRNA at specific sites. Previous studies have confirmed that abnormal expression of miRNA is closely related to malignant progression of tumor [13]. In particular, miR-137 is highly expressed in brain tissue and is associated with various brain diseases such as Alzheimer's disease and schizophrenia. Some scholars have found that miR-137 is lowly expressed in colon cancer tissues, and that it promotes the proliferation of cancer cells by regulating the expression of DCLK1 gene, suggesting that miR-137/DCLK1 signaling axis is involved in the mechanism of colon cancer etiology [14]. Notch1 signaling pathway is an evolutionally-conserved intercellular interaction mechanism that regulates cell proliferation, differentiation and maturation, and maintains cell homeostasis [15].

Mutations and changes in expression levels of this pathway protein are key factors that affect cell generation. Scholars have found that the expression of Notch receptor in breast cancer cells is significantly increased, i.e., 2 - 4 times higher than that in differentiated cells, while the expression of Notch receptor is down-regulated with the differentiation of cells [16]. In addition, other studies have found that genes related to Notch1 signaling pathway are influenced by multiple miRNA interactions, thereby affecting biological behavior [17]. The results obtained in this investigation revealed that mRNA and protein expressions of Notch1 (NICD), Hey2 and Jag1 in the miR-137 over-expressing group were significantly decreased. After transfection of Notch1 interfering plasmid into MCF7 cells, it was found that the number of cell clones and migrated cells in the Notch1 interfering + CBX4 group and miR-137 + CBX4 group were lower than those in the CBX4 group.

These results indicate that CBX4 activates the Notch1 signaling pathway through targeted regulation of $\mathrm{miR}-137$, and that interfering with Notch1 expression significantly reverses the proliferation and migration ability of breast cancer cells promoted by CBX4. Moreover, CBX4 level was accentuated in breast cancer, and it promoted cell proliferation and migration through induction of Notch1 signaling route by inhibiting miR-137 expression. These results provide a new strategy for clinical treatment of breast cancer.

\section{DECLARATIONS}

\section{Conflict of interest}

No conflict of interest is associated with this work.

\section{Contribution of authors}

We declare that this work was done by the authors named in this article and all liabilities pertaining to claims relating to the content of this article will be borne by the authors. Zhimin Fan was involved in the conception and design of the study, manuscript revision, funding support and study supervision. Le Ma contributed to design of the study as well as the experiments, data analysis and manuscript writing. Lihua Zheng, Dongmei Zhang contributed to the design of the study and interpretation of the data. All authors read and approved the final manuscript.

\section{Open Access}

This is an Open Access article that uses a funding model which does not charge readers or their institutions for access and distributed under the terms of the Creative Commons Attribution License (http://creativecommons.org/licenses/by/ 4.0) and the Budapest Open Access Initiative 
(http://www.budapestopenaccessinitiative.org/rea d), which permit unrestricted use, distribution, and reproduction in any medium, provided the original work is properly credited.

\section{REFERENCES}

1. Bray F, Ferlay J, Soerjomataram I, Siegel RL, Torre LA, Jemal A. Global cancer statistics 2018: GLOBOCAN estimates of incidence and mortality worldwide for 36 cancers in 185 countries. CA Cancer J Clin 2018; 68(6): 394-424.

2. Ghoncheh M, Pournamdar Z, Salehiniya H. Incidence and Mortality and Epidemiology of Breast Cancer in the World. Asian Pac J Cancer Prev 2016; 17(S3): 43-46.

3. Yuet-Kin L, Vinothini G, Ana C, Jennifer V, Dan S, Robin G, Xuegong Z, Jun Y, Ady K, Mario M, et al. Gestational high-fat diet and bisphenol $A$ exposure heightens mammary cancer risk. Endocr Relat Cancer 2017; 24(7): 345-358.

4. Dumanskiy YV, Bondar OV, Tkachenko OI. Comparative characteristics of quality of life in patients, suffering locally-spread mammary gland cancer after conduction of regional and intravenous chemotherapy. Klin Khir 2018; 85(6): 55-59.

5. Sancisi V, Ciarrocchi A. Role of CBX4 in the Colorectal Carcinoma Metastasis-Letter. Cancer Res 2017; 77(9): 2548-2549.

6. Kristen TT, Bart RA, Niraj S, Stephanie EZ, Daniel H, Arielle NV, Qiaochu G, Gary JB. Inhibition of the Schizophrenia-Associated MicroRNA miR-137 Disrupts Nrg1a Neurodevelopmental Signal Transduction. Cell Rep 2017; 20(1): 1-12.

7. Zhang HS, Zhang ZG, Du GY, Sun HL, Liu HY, Zhou Z, Gou $X M$, Wu XH, Yu XY, Huang YH. Nrf2 promotes breast cancer cell migration via up-regulation of G6PD/HIF-1alpha/Notch1 axis. J Cell Mol Med 2019; 23(5): 3451-3463.

8. Kim SS, Ahn SD, Choi EK, Jeong Y. Results of Ultrasonography-Guided Fine Needle Aspiration of Internal Mammary Lymph Node for Breast Cancer Patients Who Received Neoadjuvant Chemotherapy. Int J Radiat Oncol Biol Phys 2017; 99(2): 23-24.
9. Wang X, Kang T. Role of CBX4 in the Colorectal Carcinoma Metastasis-Response. Cancer Res 2017; 77(9): 2550-2551.

10. Zengliang Z, Nan L, Xing W, Bingyao C, Yinglong Z, Yantao $Z$, Xiantong $H$, Shuxun H. GRM4 inhibits the proliferation, migration, and invasion of human osteosarcoma cells through interaction with CBX4. Biosci Biotechnol Biochem 2019, 84(1):1-11.

11. Xiaoqing $R$, Boqiang $H$, Moshi $S$, Zhichao $D$, Yujiao $D$, Zunpeng L, Weiqi Z, Qianzhao J, Ruotong R, Jianjian D. Maintenance of Nucleolar Homeostasis by CBX4 Alleviates Senescence and Osteoarthritis. Cell Rep 2019; 26(13): 3643-3656.

12. Haoran $W$, Xugang $W$, Naixin M, Liang Z, Xiaoliang $Y$, Zhong L. B7-Homolog 4 Promotes Epithelial-Mesenchymal Transition and Invasion of Bladder Cancer Cells via Activation of Nuclear FactorKB. Oncol Res Featuring Preclinical Clin Cancer Ther 2018; 26(8): 1267-1274.

13. He T, Li X, Lu D, Tian L, Xu B. MiR-137 silencing of $B R D 4$ suppresses oral squamous cell carcinoma cells proliferation, migration and invasion. Int $\mathrm{J}$ Clin Exp Pathol 2017; 10(1): 409-416.

14. Cheng S, Huang Y, Lou C, et al. FSTL1 enhances chemoresistance and maintains stemness in breast cancer cells via integrin $\beta 3 / W n t$ signaling under miR-137 regulation. Cancer Biol Ther 2019; 20(3): 328-337.

15. Shaoqiang C, Yuanxi $H$, Chun L, Yanxia H, Yue Z, Qingyuan Z. The NOTCH1-MYC highway toward T-cell acute lymphoblastic leukemia. Blood 2017; 129(9): 1124-1133.

16. Pozzo F, Bittolo $T$, Vendramini $E$, Bomben $R$, Bulian $P$, Rossi FM, Zucchetto A, Tissino E, Degan M, Arena GD, et al. NOTCH1-mutated chronic lymphocytic leukemia cells are characterized by a MYC-related overexpression of nucleophosmin 1 and ribosomeassociated components. Leuk 2017; 31(S2): 57-58.

17. Morrugares R, Correa-Sáez A, Moreno R, GarridoRodríguez $M$, Muñoz E, de la Vega L, Calzado MA. Phosphorylation-dependent regulation of the NOTCH1 intracellular domain by dual-specificity tyrosineregulated kinase 2. Cell Mol Life Sci 2020; 77(13): 26212639. 